\title{
Current exposure of 200 pregnant Danish women to phthalates, parabens and phenols
}

\author{
Katrine Tefre de Renzy-Martin, Hanne Frederiksen, Jeppe Schultz Christensen, \\ Henriette Boye Kyhl ${ }^{1}$, Anna-Maria Andersson, Steffen Husby ${ }^{1}$, Torben Barington ${ }^{2}$, \\ Katharina M Main and Tina Kold Jensen ${ }^{3}$
}

University Department of Growth and Reproduction, Section 5064, Rigshospitalet, Blegdamsvej 9, 2100 Copenhagen, Denmark, ${ }^{1}$ Odense University Hospital, Hans Christian Andersen Children's Hospital, Sdr. Boulevard 29, 5000 Odense C, Denmark, ${ }^{2}$ OPEN (Odense Patient data Exploratory Network), Odense University Hospital, Sdr. Boulevard 29, 5000 Odense C, Denmark and ${ }^{3}$ Department of Environmental Medicine, University of Southern Denmark, Winsløwparken 17, 5000 Odense C, Denmark

Correspondence should be addressed to TK Jensen; Email: tkjensen@health.sdu.dk

(This work was carried out at Affiliations 1 and 2)

\begin{abstract}
Many phthalates, parabens and phenols are suspected to have endocrine-disrupting properties in humans. They are found in consumer products, including food wrapping, cosmetics and building materials. The foetus is particularly vulnerable and exposure to these chemicals therefore is of concern for pregnant women. We investigated current exposure to several commonly used phthalates, parabens and phenols in healthy, pregnant Danish women. A total of 200 spot urine samples were collected between 8 and 30 weeks of gestation and analysed for metabolites of ten phenols, seven parabens and 16 phthalate by liquid chromatography-tandem mass spectrometry representing 26 non-persistent compounds. The majority of analytes were present in the urine sample collected from most women who participated. Thus, in 174 of the 200 women, metabolites of more than $13(>50 \%)$ of 26 compounds were detected simultaneously. The number of compounds detected per woman (either as the parent compound or its metabolite(s)) ranged from 7 to 21 with a median of 16. The majority of compounds correlated positively with each other within and between chemical groups, suggesting combined exposure sources. Estimated daily intakes (DIs) of phthalates and bisphenol A (BPA) were below their individual tolerable DI (TDI) and with hazard quotients below 1. In conclusion, we found detectable levels of phthalate metabolites, parabens and phenols in almost all pregnant women, suggesting combined multiple exposures. Although the estimated DI of phthalates and BPA for an individual was below TDI, our results still raise concern, as current toxicological risk assessments in humans do not take into account simultaneous exposure. The true cumulative risk for the foetus may therefore be underestimated.
\end{abstract}

Reproduction (2014) $\mathbf{1 4 7}$ 443-453

\section{Introduction}

During recent years, evidence that both humans and wildlife are exposed to a wide range of

\footnotetext{
This paper forms part of a special issue of Reproduction on Endocrine Disrupters. This article was presented at the 7 th Copenhagen Workshop on Endocrine Disrupters, 28-31 May 2013. The meeting was supported by the Danish Ministry of the Environment - Environmental Protection Agency as an activity under the Danish Centre on Endocrine Disrupters. Publication of this special issue has been supported by the Society for Reproduction and Fertility. The opinions or views expressed in this special issue are those of the authors, and do not necessarily reflect the opinions or recommendations of the Danish Ministry of the Environment - Environmental Protection Agency or the Society for Reproduction and Fertility. The Guest Editors for this special issue were Anna-Maria Andersson, Hanne Frederiksen, Niels Erik Skakkebæk, Rigshospitalet, Denmark, Kenneth M Grigor, Western General Hospital, Edinburgh, UK and Jorma Toppari, University of Turku, Finland.
}

endocrine-disrupting chemicals (EDCs) has been mounting. Exposure of pregnant women is of particular concern because of the potential health impact on the vulnerable foetus, in which exposure may inflict lifelong adverse health effects. Some of these chemicals have been shown to cross the placenta, enter the foetus and recycle via amniotic fluid (Bradman et al. 2003, Mose et al. 2007, Morck et al. 2010). Thus, a number of chemicals measured in maternal urine, serum and breast milk have also been found in amniotic fluid, cord blood and meconium (Ikezuki et al. 2002, Main et al. 2006, Barr et al. 2007, Jensen et al. 2012). A recent study has reported detectable levels of metabolites from two common phthalate diesters, di(2-ethylhexyl) (DEHP) and di-isononyl phthalate (DiNP), and perfluorooctanesulfonic acid in amniotic fluid collected from Danish women (Jensen et al. 2012). 
Phthalates, phenols and parabens are non-persistent chemicals, to which humans are exposed life-long and ubiquitously due to their widespread application in many modern consumer products, i.e. in food, plastics including food packaging, fabrics, personal care items, cosmetics and building materials (Golden et al. 2005, Chapin et al. 2008, Wittassek et al. 2011, Jung et al. 2012, National Center for Biotechnology Information, www.ncbi.nlm.nih.gov/pmc/articles/PMC2453187/pdf/ ehp0116-a0306a.pdf, last accessed Sep 2013).

Rodent and human data suggest adverse health effects of phthalates, in particular anti-androgenic effects on male reproductive development after prenatal exposure (Swan et al. 2005, Main et al. 2006, DesdoitsLethimonier et al. 2012).

Among the group of phenols, bisphenol A (BPA) is the most intensively studied compound, which shows adverse effects on reproduction, thyroid gland and the immune system in both human and animals (Vandenberg et al. 2009). BPA is used in polycarbonate and epoxy resins (Chapin et al. 2008). Triclosan (TCS), benzophenone-3 (BP-3) (a u.v.-filter) and several other phenols also appear to have endocrine-disrupting activity with adverse effects on, e.g. thyroid and reproductive function (Zhang et al. 2008, Li et al. 2010, Rodriguez \& Sanchez 2010, Jung et al. 2012, Krause et al. 2012, Henry \& Fair 2013).

Parabens are widely used as anti-microbial preservatives (Rastogi et al. 1995, European Food Safety Authority (EFSA) 2004, Golden et al. 2005, Soni et al. 2005), often as mixtures. Data on exposure levels and health effects in humans are sparse, but parabens have shown to exhibit estrogenic properties in animal studies (Boberg et al. 2010) and appear to accumulate in amniotic fluid (Frederiksen et al. 2008).

In this study, we aimed to describe the current exposure of pregnant Danish women to phthalates, parabens and phenols in order to evaluate whether there is reason for concern with respect to potential adverse effects on the foetus.

\section{Materials and methods}

\section{Study population and sample collection}

The Odense Child Cohort is a collaborative study between Odense Municipality, Odense University Hospital and the University of Southern Denmark. All pregnant women and their partners living in the catchment area of Odense Municipality were invited to participate from January 2010 to December 2012 at an information meeting about pregnancy in gestational weeks 10-16. The women were followed through pregnancy and the children are planned to be followed with repetitive examinations until the age of 18 years. Given the general demographics of Odense Municipality, the majority of the women are white Caucasian and $92.3 \%$ were born in Denmark. At enrolment a serum sample was collected and the women completed a comprehensive questionnaire about general health, lifestyle and social factors including age, pre- pregnancy height, weight (from which the BMI was calculated), parity, marital status and education (high school or less; high school $+1-3$ years; and high school +4 years or more). In gestational weeks $8^{+0}-30^{+0}$, a spot urine sample was collected and the women responded to another questionnaire. The participation rate is $51 \%$.

In this study, urine samples from 200 women, collected between February 1st and June 7th, 2011, have been analysed for the content of phthalates, phenols and parabens. To avoid sample contamination during collection and storage, urines were collected in polyethylene containers and stored at $-20^{\circ} \mathrm{C}$ as $10-\mathrm{ml}$ aliquots in $20-\mathrm{ml}$ glass scintillation vials with tops packed with aluminium foil.

The study was conducted in accordance with Helsinki declaration II and approved by the regional ethical committee (the Ethics Committee for Biomedical Research in The Region of Southern Denmark S-20090130). After having received written and oral information, all participants gave their written consent.

\section{Chemical analyses}

BPA and other phenols

The urinary content of total (free and conjugated) BPA, TCS, triclocarban (TCCB), BP-3, 2,4-dichlorophenol (2,4-DCP), 2,5DCP, 2,4,5-trichlorophenol (2,4,5-TCP), 2-phenylphenol (2-PP), 4-PP and 4-tert-octylphenol (4-tOP) was analysed by a newly developed method for simultaneous quantitative determination using isotope dilution TurboFlow-liquid chromatography-tandem mass spectrometry (LC-MS/MS) with preceding enzymatic deconjugation (Frederiksen et al. 2013). The first 50 urine samples were analysed in two batches with few days in between. In these samples 2,4-DCP and 2,5-DCP were analysed as one analyte ( $\mathrm{DDCP})$. The next 150 samples were analysed 3 months later in four batches during a period of 8 days. In these samples, 2,4-DCP and 2,5-DCP were separated. In short, each batch included standards for calibration curves, 25-30 unknown samples, two blanks, two urine pool controls and two urine pool controls spiked with phenol standards at low and high level respectively. The interday variation, expressed as the relative standard deviation (RSD), was $<11 \%$ for most analytes in both spiked samples except for TCCB $(<16 \%)$, BP-3 $(<21 \%)$ and 4 -tOP $(<25 \%)$. The recovery of spiked samples was $>96 \%$ for all analytes except for TCS (82\%), 2,5-DCP (91\%) and 4-tOP (84\%).

\section{Parabens}

The total content (free and conjugated) of methylparaben $(\mathrm{MeP})$, ethylparaben (EtP), $n$-propylparaben $(n$-PrP), isopropylparaben (i-PrP), $n$-butylparaben $(n$-BuP), iso-butylparaben (i-BuP) and benzylparaben (BzP) was simultaneously analysed by LC-MS/MS as previously described by Frederiksen et al. (2011) with the following modification in order to separate i-PrP and $n$-PrP, and i-BuP and $n$-BuP, respectively, the solvent gradient described in Frederiksen et al. (2010) for a LC-MS/MS method for phthalate metabolites was used. The retention time periods for the analytes were $6.2 \mathrm{~min}(\mathrm{MeP})$, $8.6 \mathrm{~min}(\mathrm{EtP}), 12.0 \mathrm{~min}(\mathrm{i}-\mathrm{PrP}), 12.6 \mathrm{~min}(n-\operatorname{PrP}), 17.0 \mathrm{~min}$ 
(i-BuP), $17.4 \mathrm{~min}(n-\mathrm{BuP})$ and $18.7 \mathrm{~min}(\mathrm{BzP})$. In this study all urine samples were analysed in six batches during a period of 2 weeks. In short, each batch included standards for calibration curves, 35-40 unknown samples, two blanks, two urine pool controls and two urine pool controls spiked with paraben standards at low and high level respectively. The interday variation, expressed as the RSD, was $<12 \%$ and the recovery of spiked samples was $>90 \%$ for all parabens at low and high spike levels.

\section{Phthalates}

Urine samples were analysed for the total content (free and glucuronidated) of 16 phthalate metabolites: monoethyl phthalate (MEP), mono-iso-butyl phthalate (MiBP), mono$n$-butyl phthalate (MnBP), monobenzyl phthalate (MBzP), mono- $n$-pentyl phthalate (MPP), mono(2-ethylhexyl) phthalate (MEHP), mono(2-ethyl-5-hydroxyhexyl) (MEHHP), mono(2ethyl-5-oxohexyl) phthalate (MEOHP), mono(2-ethyl-5carboxypentyl) phthalate (MECPP), mono- $n$-octyl phthalate (MOP), mono(3-carboxypropyl) phthalate (MCPP), monoiso-nonyl phthalate (MiNP), mono(hydroxy-iso-nonyl) phthalate (MHiNP), mono(oxo-iso-nonyl) phthalate (MOiNP), mono(carboxy-iso-octyl) phthalate (MCiOP) and monoiso-decyl phthalate (MiDP) by LC-MS/MS with preceding enzymatic deglucuronidation followed by solid-phase extraction. The method for the preparation of samples, standard solutions and quality controls, as well as the instrumental analysis and general validation method, has previously been described in detail (Frederiksen et al. 2010). In this study, samples were analysed in six batches during a two-week period. In short, each batch included standards for calibration curves, about 35 unknown samples, two blanks, two urine pool controls and two urine pool controls spiked with phthalates standards at low level. The inter-day variation, expressed as the RSD, was $<12 \%$ for all analytes except MiDP (14.5\%) and the recovery of spiked samples was $>90 \%$ for all analytes except MnBP (82\%), MPP (85\%) and MiDP (87\%). Creatinine was determined in all urine samples by colorimetric enzymatic assay (Roche Diagnostics $\mathrm{GmbH}$ ).

\section{Statistical analysis}

The measured concentrations ( $\mathrm{ng} / \mathrm{ml}$ ) of each compound are presented as 25th, 50th and 95th percentiles, minimum and maximum levels. To adjust for variation in urinary dilution, all concentrations were creatinine-adjusted using the following equation:

$\mathrm{UE}_{\text {crea }}\left(\frac{\mu \mathrm{g}}{\mathrm{g}_{\text {crea }}}\right)=\frac{\mathrm{UC}\left(\frac{\mu \mathrm{g}}{\mathrm{L}}\right) \times 1000\left(\frac{\mathrm{mg}}{\mathrm{g}}\right)}{\mathrm{UC}_{\text {crea }}\left(\frac{\mathrm{mmol}}{\mathrm{L}}\right) \times \mathrm{MW}_{\text {crea }}\left(\frac{\mathrm{mg}}{\mathrm{mmol}}\right)}$

where $U E_{\text {crea }}$ is the creatinine-adjusted urinary analyte $(\mu \mathrm{g} / \mathrm{g})$ and $\mathrm{UC}$ is the measured urinary concentration of the compounds. $\mathrm{UC}_{\mathrm{crea}}$ and $\mathrm{MW}_{\mathrm{crea}}$ are the urinary concentration and the molar mass $(113.12 \mathrm{mg} / \mathrm{mmol})$ of creatinine respectively.

In order to estimate the daily intake (DI) of BPA per kilo body weight per day, the following equation was used with the assumption that BPA was almost completely excreted in urine within $24 \mathrm{~h}$ (Volkel et al. 2002, Fisher et al. 2011):

$\mathrm{DI}(\mu \mathrm{g} / \mathrm{kg}$ per day $)=\frac{\mathrm{UE}_{\text {crea }}\left(\frac{\mu \mathrm{g}}{\mathrm{g}_{\text {crea }}}\right) \times \mathrm{CE}_{\text {smoothed }}\left(\frac{\mathrm{g}}{\text { day }}\right)}{\mathrm{BW}(\mathrm{kg})}$

where $\mathrm{CE}_{\text {smoothed }}$ is an average reference value $(1.12 \mathrm{~g} /$ day) for urinary creatinine excretion for pregnant women in gestational weeks 25-28 (Gallery et al. 1996) and BW is selfreported pre-pregnancy body weight. The same equation was used for the parabens and the rest of the phenols in order to estimate the daily excretion with the assumption of an excretion factor of $100 \%$ because of lack of human pharmacokinetic studies.

Estimation of DI for phthalate diesters per kilo body weight per day was calculated as:

$$
\begin{aligned}
& \mathrm{DI}(\mu \mathrm{g} / \mathrm{kg} / \text { day })
\end{aligned}
$$

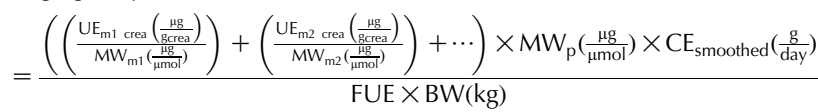

where $U E_{m 1}$ crea, $U E_{m 2}$ crea $M W_{m 1}$ and $M W_{m 2}$ are the creatinine-adjusted urinary concentrations of phthalate metabolites and their respective molar masses; $M W_{p}$ is the molar mass of the specific phthalate diester and FUE is the fraction of the phthalate diester excreted in urine. The fractional urinary excretion (FUE) factors were based on previous human studies of urinary excretion after oral intake of deuterium-labelled phthalate diesters, where $69 \%$ of di- $n$-butyl phthalate (DnBP) was excreted as MnBP, $73 \%$ of butylbenzyl phthalate (BBzP) as $\mathrm{MBzP}, 45.3 \%$ of DEHP was excreted as common DEHP metabolites (MEHP, MEHHP, MEOHP and MECPP) and $30.5 \%$ of DiNP as common DiNP metabolites (MiNP, MHiNP, MOiNP and MCiOP) (Anderson et al. 2001, 2011, Wittassek et al. 2011). FUEs for di-ethyl phthalate (DEP) and di-iso-butyl phthalate (DiBP) were assumed to be the same as for DnBP (Koch \& Calafat 2009).

Estimated DIs were divided by the tolerable DI (TDI) to produce the hazard quotient $(\mathrm{HQ})$ for four of the phthalates: DnBP, BBzP, DEHP and DiNP. These HQs were then added to produce the hazard index (HI; Soeborg et al. 2012). The HQs and HIs are presented as 25th, 50th and 95th percentiles as well as the minimum and maximum levels.

Maternal age and pre-pregnancy BMI were categorised into three groups (see Table 1). We used Spearman's rank correlation coefficients for the analysis of associations between different chemicals, and to test associations between maternal characteristics (age and BMI) and exposure levels. To compare chemical levels across the groups (education and parity), nonparametric Mann-Whitney U-tests were used. A total of $95 \%$ of the women had creatinine levels within the normal range and the analyses were repeated among these women. All statistical tests were evaluated at a $5 \%$ significance level. SPSS (version 18.0, SPSS) was used for all analyses.

\section{Results}

Characteristics of the study population are shown in Table 1. Information on height, parity and pre-pregnancy 
Table 1 Characteristics of 200 Danish pregnant women, 2011.

\begin{tabular}{|c|c|c|}
\hline Characteristics & $n(\%)$ & Median (range) \\
\hline Maternal age (years) & & $30.2(18.5-40.3)$ \\
\hline$<25$ & $20(10)$ & \\
\hline $25-35$ & $147(73)$ & \\
\hline$>35$ & $33(17)$ & \\
\hline Maternal height $(\mathrm{cm}), n=183$ & & $168(164-185)$ \\
\hline $\begin{array}{l}\text { Maternal pre-pregnancy } \\
\text { weight }(\mathrm{kg}), n=181\end{array}$ & & $67(44-124)$ \\
\hline Pre-pregnancy BMI (kg/m²) & & $23.9(17.8-41.4)$ \\
\hline$<18.5$ & $4(2)$ & \\
\hline $18.5-24.9$ & $106(59)$ & \\
\hline$>25$ & $71(39)$ & \\
\hline \multicolumn{3}{|l|}{ Maternal education } \\
\hline High school or less & $49(27)$ & \\
\hline High school $+1-3$ years & $109(59)$ & \\
\hline High school +4 years or more & $25(14)$ & \\
\hline \multicolumn{3}{|l|}{ Marital status } \\
\hline Married or living with a partner & $178(98)$ & \\
\hline Single/divorced/widowed & $3(2)$ & \\
\hline \multicolumn{3}{|l|}{ Parity $(n=182)$} \\
\hline 0 & $98(54)$ & \\
\hline$\geq 1$ & $84(46)$ & \\
\hline
\end{tabular}

weight was not available for 17, 18 and 19 of the women, respectively, either because they did not fill out the prenatal questionnaire or because they joined the study after gestational week 26 .

\section{Urinary levels of chemicals}

Unadjusted and creatinine-adjusted median urinary concentrations of the 33 analytes measured are presented in Table 2 along with selected percentiles, minimum and maximum levels, as well as percentage of samples greater than limit of detection (LOD) for each analyte. Molar median concentrations for the most prevalent analytes are shown in Fig. 1 for comparison.

The 33 analytes represent 26 non-persistent chemicals, as some of the analytes were phthalate metabolites of the same parent compound. The majority of analytes were present in urine collected from most women. In 174 of 200 women, metabolites of more than $13(>50 \%)$ of the 26 parent compounds were detected simultaneously. The number of compounds per woman (either as the parent compound or its metabolite(s)) ranged from 7 to 21 with a median of 16 .

Only two analytes (4-tOP and iBuP) were not detectable at all. Other analytes, which were only detectable in a limited number of samples, were 4-PP, iPrP, BzP, and the metabolites MPP, MOP and MiDP. These analytes were not further evaluated.

\section{Associations between chemicals}

For parabens, concentrations of $n-\operatorname{PrP}$ and $\mathrm{MeP}$ were highly correlated $(\rho=0.822, P<0.01)$. All other parabens also correlated positively $(\rho=0.443-0.562, P<0.01)$.
We observed several positive correlations between phenols $(\rho=0.146-0.644, P<0.05)$, of which BPA, TCS, TCCB, BP-3, 2,4-DCP and 2,4,5-TCP also correlated positively with several parabens (MeP, EtP, $n$-PrP and $n$-BuP), $(\rho=0.143-0.420, P<0.05)$.

The phthalates generally correlated positively with each other $(\rho=0.272-0.971, P<0.01)$ as well as with parabens $(\rho=0.142-0.373, P<0.05)$ and most phenols $(\rho=0.140-0.519, P<0.05)$.

\section{Associations between chemicals and maternal characteristics}

Pre-pregnancy BMI was positively associated with 12 out of the 13 phthalate metabolites $(\rho=0.164-0.317$, $P<0.05)$ and four phenols (BPA, 2,4-DCP, 2,4,5-TCP and 2-PP) $(\rho=0.153-0.209, P<0.05)$. None of the analytes were consistently associated with maternal age, education or parity.

\section{Estimates of DI and daily excretion}

The estimated DI for BPA and six phthalate diesters and the daily excretion for parabens and other phenols are presented in Table 3 along with the EFSA TDI levels for DnBP, BBzP, DEHP, DiNP and BPA. None of the analytes were above the TDI. In Table 4, the HQs based on EFSA TDI values are given along with the corresponding HIs. None of the pregnant women exceeded the value of 1 . Repeating the analyses among $95 \%$ of the women with creatinine levels within the normal range did not change the estimation.

\section{Discussion}

In recent years increasing attention has been given to volatile compounds such as phthalates and parabens for their potential endocrine-disrupting properties. In this contemporary study of urinary excretion of 26 nonpersistent environmental chemicals in healthy Danish pregnant women, the average woman was simultaneously exposed to the majority of the studied chemicals. A high urinary concentration of one chemical in an individual was often associated with high concentrations of several other chemicals, suggesting a common exposure source or common exposures associated with specific lifestyles. Several chemicals are known or some are suggested EDCs that may target the same hormonal axis. The simultaneous exposure to many different EDCs is of concern, as animal studies have shown that dose-additive effects are to be expected from EDCs affecting the same hormone system (e.g. different phthalates; Gray et al. 2006, Christiansen et al. 2009, 2012).

Individual concentrations of some phenols, parabens and phthalates varied considerably between 
Table 2 Concentration of phenols, parabens and phthalate metabolites in the urine samples collected from pregnant Danish women $(n=200)$ at gestational weeks $8-30$, given as $\mu \mathrm{g} / \mathrm{l}$ and $\mu \mathrm{g} / \mathrm{g}$ creatinine.

\begin{tabular}{|c|c|c|c|c|c|c|c|c|c|c|c|c|}
\hline \multirow[b]{3}{*}{ Compound } & & \multicolumn{7}{|c|}{ Unadjusted $(\mu \mathrm{g} / \mathrm{l})$} & \multirow{2}{*}{\multicolumn{4}{|c|}{$\begin{array}{c}\text { Creatinine adjusted }(\mu \mathrm{g} / \mathrm{g}) \\
\text { Percentiles }\end{array}$}} \\
\hline & & \multirow[b]{2}{*}{ LOD } & \multirow{2}{*}{$\begin{array}{c}n(\%) \\
>\text { LOD }\end{array}$} & \multirow[b]{2}{*}{ Min. } & \multicolumn{3}{|c|}{ Percentiles } & \multirow[b]{2}{*}{ Max. } & & & & \\
\hline & & & & & 25 & 50 & 95 & & 25 & 50 & 95 & Max \\
\hline \multicolumn{13}{|l|}{ Phenols } \\
\hline $\mathrm{BPA}$ & & 0.12 & $179(89.5)$ & $<$ LOD & 0.56 & 1.38 & 5.61 & 25.2 & 0.57 & 1.18 & 5.24 & 68.4 \\
\hline TCS & & 0.06 & $171(85.5)$ & $<$ LOD & 0.21 & 0.70 & 438 & 1220 & 0.20 & 0.63 & 432 & 1435 \\
\hline TCCB & & 0.01 & $108(54)$ & & $<$ LOD & 0.02 & 0.42 & 0.68 & $<0.01$ & 0.02 & 0.54 & 2.29 \\
\hline BP-3 & & 0.07 & 194 (97) & $<\mathrm{LOD}$ & 1.17 & 3.20 & 402 & 7753 & 1.27 & 2.99 & 944 & 6283 \\
\hline $2,4-D C P^{a}$ & & 0.07 & $124(82.7)$ & $<$ LOD & 0.10 & 0.24 & 1.35 & 4.82 & 0.10 & 0.20 & 1.08 & 4.04 \\
\hline $2,5-D C P^{a}$ & & 0.07 & $96(64)$ & & $<$ LOD & 0.15 & 1.48 & 15.4 & $<0.01$ & 0.13 & 1.07 & 13.2 \\
\hline$\Sigma \mathrm{DCP} \mathrm{P}^{\mathrm{b}}$ & & 0.07 & $31(62)$ & & $<\mathrm{LOD}$ & 0.24 & 1.34 & 1.41 & $<0.01$ & 0.16 & 1.85 & 2.60 \\
\hline $2,4,5-\mathrm{TCP}$ & & 0.06 & 99 (49.5) & & $<$ LOD & 0.04 & 0.99 & 3.88 & & $<0.01$ & 0.82 & 3.76 \\
\hline 2-PP & & 0.12 & $124(62)$ & & $<$ LOD & 0.19 & 0.87 & 3.03 & $<0.01$ & 0.16 & 0.75 & 2.60 \\
\hline 4-PP & & 0.13 & 27 (13.5) & & & $<\mathrm{LOD}$ & 1.20 & 7.01 & & $<0.01$ & 0.95 & 4.44 \\
\hline 4-tOP & & 0.87 & 0 & & & & & & & & & \\
\hline \multicolumn{13}{|l|}{ Parabens } \\
\hline MeP & & 0.26 & 190 (95) & $<$ LOD & 4.09 & 20.7 & 474 & 3066 & 5.05 & 20.5 & 357 & 2950 \\
\hline EtP & & 0.40 & $120(60)$ & & $<$ LOD & 1.01 & 49.7 & 291 & $<0.01$ & 0.88 & 40.3 & 156 \\
\hline i-PrP & & 0.18 & $15(7.5)$ & & & $<\mathrm{LOD}$ & 0.91 & 15.7 & & $<0.01$ & 1.33 & 13.3 \\
\hline$n-\operatorname{PrP}$ & & 0.18 & 166 (83) & $<$ LOD & 0.61 & 4.17 & 199 & 646 & 0.68 & 4.69 & 144 & 346 \\
\hline i-BuP & & 0.07 & 0 & & & & & $<$ LOD & & & & \\
\hline$n$-BuP & & 0.07 & $76(38)$ & & & $<\mathrm{LOD}$ & 13.0 & 87.5 & & $<0.01$ & 12.9 & 62.7 \\
\hline $\mathrm{BzP}$ & & 0.18 & $16(8)$ & & & $<$ LOD & 0.30 & 2.35 & & $<0.01$ & 0.33 & 1.91 \\
\hline \multicolumn{13}{|c|}{ Phthalate metabolites } \\
\hline $\begin{array}{l}\text { Diester } \\
\text { phthalate }\end{array}$ & $\begin{array}{l}\text { Urinary } \\
\text { metabolite }\end{array}$ & & & & & & & & & & & \\
\hline DEP & MEP & 0.53 & 199 (100) & $<\mathrm{LOD}$ & 7.49 & 21.5 & 470 & 2710 & 9.04 & 18.9 & 355 & 2190 \\
\hline DiBP & МiBP & 1.43 & 200 (100) & 1.46 & 19.2 & 39.8 & 159 & 455 & 24.7 & 35.3 & 98.3 & 274 \\
\hline DnBP & $\mathrm{MnBP}$ & 1.10 & $196(98)$ & $<$ LOD & 7.24 & 16.0 & 58.8 & 184 & 9.09 & 13.9 & 37.5 & 124 \\
\hline BBzP & MBzP & 1.14 & $154(77)$ & $<$ LOD & 1.20 & 2.97 & 20.4 & 546 & 1.08 & 2.32 & 17.5 & 230 \\
\hline DPP & MPP & 0.81 & $3(1.5)$ & & & & $<$ LOD & 5.48 & & & $<0.01$ & 3.37 \\
\hline \multirow{4}{*}{ DEHP } & MEHP & 0.14 & $175(88)$ & $<$ LOD & 0.43 & 1.15 & 5.80 & 61.1 & 0.45 & 1.12 & 3.82 & 25.8 \\
\hline & MEHHP & 0.91 & 187 (94) & $<$ LOD & 3.34 & 6.25 & 20.3 & 121 & 3.54 & 5.70 & 13.4 & 51.0 \\
\hline & MEOHP & 0.67 & $187(94)$ & $<$ LOD & 2.30 & 4.32 & 13.6 & 106 & 2.41 & 3.72 & 9.22 & 44.9 \\
\hline & MECPP & 0.55 & $192(96)$ & $<$ LOD & 3.15 & 5.49 & 15.9 & 95.7 & 3.32 & 4.75 & 10.1 & 54.1 \\
\hline \multirow{2}{*}{ DOP } & MOP & 0.15 & $1(0.5)$ & & & & $<$ LOD & 1.40 & & & $<0.01$ & 0.92 \\
\hline & МCPP & 0.36 & $190(95)$ & $<\mathrm{LOD}$ & 1.34 & 2.62 & 9.88 & 346 & 1.41 & 2.16 & 9.75 & 195 \\
\hline \multirow[t]{4}{*}{ DiNP } & MiNP & 0.61 & $22(11)$ & & & $<$ LOD & 1.88 & 98.2 & & $<0.01$ & 1.26 & 55.5 \\
\hline & MHiNP & 0.26 & $180(90)$ & $<\mathrm{LOD}$ & 0.79 & 1.71 & 20.7 & 800 & 0.75 & 1.47 & 11.5 & 453 \\
\hline & MOiNP & 0.25 & 170 (85) & $<$ LOD & 0.53 & 1.21 & 11.0 & 472 & 0.45 & 1.02 & 8.90 & 267 \\
\hline & MCiOP & 0.11 & $200(100)$ & 0.21 & 2.44 & 4.00 & 39.6 & 1332 & 2.37 & 3.65 & 34.9 & 753 \\
\hline DiDP & MiDP & 0.69 & $1(0.5)$ & & & & $<$ LOD & 9.84 & & & $<0.01$ & 5.56 \\
\hline
\end{tabular}

LOD, limit of detection; $n$, number of samples.

${ }^{\mathrm{a}} n=150$. ${ }^{\mathrm{b}}$ Sum of 2,4-DCP and 2,5-DCP $(n=50)$.

participants, indicating large differences in environmental exposure possibly due to personal housing conditions and life-style factors. For instance, TCS and BP-3 both showed a very wide range with a minimum less than LOD and a maximum of 1220 and $7753 \mu \mathrm{g} / \mathrm{l}$ respectively. This may indicate that it is possible to reduce the exposure to some of these chemicals by identifying exposure routes and changing habits.

Urinary levels measured in Danish women was compared with previously published studies (Tables 5 and 6). Although absolute values may differ due to types of sampling, national differences in regulations of industrial chemical production and application over time, and differences in study population, some patterns are nevertheless apparent.
Our reported median concentration of urinary BPA is within the same order of magnitude as previously reported across Europe and USA, thus indicating a fairly consistent environmental exposure (Table 5). In contrast, TCS and BP-3 measurements from pregnant women differed considerably between countries, indicating regional differences in the use of, e.g. TCS as a disinfectant in personal care products (Table 5). Our samples collected between March and June show no discernible variation of BP-3 concentration over time (data not shown). Exposure during this period of the year may come from other sources than sunscreen, as BP-3 is also applied as u.v. stabiliser in plastics, food and household products to prevent photodegradation (Krause et al. 2012, National Center for Biotechnology Information, www.ncbi.nlm.nih.gov/pmc/articles/PMC2453187/pdf/ 


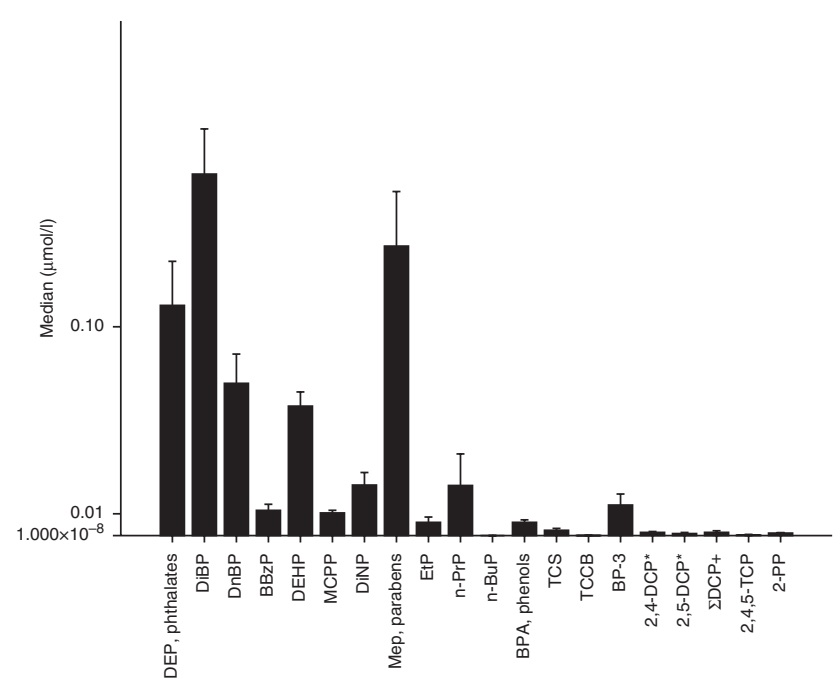

Figure 1 Median (95\% error bars) concentrations ( $\mu \mathrm{mol} / \mathrm{l}$ ) of phthalate metabolites, phenols and parabens detected in 200 pregnant Danish women (note the logarithmic Y-axis). ${ }^{*} n=150 .{ }^{+}$Sum of 2,4 -DCP and 2,5-DCP, $n=50$.

ehp0116-a0306a.pdf, last accessed Sep 2013). French and Spanish pregnant women and American women had higher paraben concentrations than the Danish women in our study (Calafat et al. 2006, Casas et al. 2011, Philippat et al. 2012). In another recent Danish study, young men had slightly lower paraben levels than the pregnant women in this study (Frederiksen et al. 2011). Americans have a slightly different phthalate excretion pattern than
Danish and German women, with a higher excretion of MEP and lower MBP (Table 6). Such regional differences in excretion patterns may reflect national variations of industrial application or different consumer patterns of products containing phthalates. Phthalate metabolite levels measured in this study were generally lower than previously published studies performed among pregnant women in different countries (Table 6). This may be due to regional differences but could also reflect a more restricted use of phthalate over recent years, resulting in declining exposure.

In order to evaluate the potential risk of the observed exposures, including an evaluation of the risk of the combined exposures, we attempted to estimate the DI of individual chemicals based on creatinine-adjusted spot urine measures. This poses several challenges. Owing to an expected significant diurnal variability of urinary concentrations of non-persistent chemicals, e.g. BPA (Ye et al. 2011), this approach may lead to over-or underestimation of the true total 24-h urinary excretion, making extreme values less reliable. The estimation also relies on an average daily creatinine excretion, which may change throughout pregnancy due to changes in creatinine metabolism and excretion. However, these changes have been reported to be minimal (Gallery et al. 1996). In addition, exclusion of the $5 \%$ of women with creatinine levels above the normal values did not change the findings. Furthermore, the estimates of DI and excretion were based on self-reported prepregnancy weight, which is not an optimal parameter.

Table 3 Estimated DI of BPA and phthalate diesters ( $\mu$ g/kg BW per day) in Danish pregnant women in 2011, based on urinary excretion levels $(n=181)$.

\begin{tabular}{|c|c|c|c|c|c|c|}
\hline \multirow[b]{2}{*}{ Compound } & \multirow[b]{2}{*}{ Min. } & \multicolumn{3}{|c|}{ Percentiles } & \multirow[b]{2}{*}{ Max. } & \multirow[b]{2}{*}{ TDI $^{\mathrm{a}}$} \\
\hline & & 25 & 50 & 95 & & \\
\hline \multicolumn{7}{|c|}{ Phthalate diester } \\
\hline DEP & & 0.24 & 0.51 & 11.5 & 63.6 & \\
\hline DiBP & 0.20 & 0.71 & 1.13 & 2.95 & 6.72 & \\
\hline DnBP & & 0.27 & 0.41 & 1.17 & 3.51 & 10 \\
\hline $\mathrm{BBzP}$ & & 0.04 & 0.07 & 0.55 & 4.45 & 500 \\
\hline DEHP & & 0.50 & 0.75 & 1.79 & 5.38 & 50 \\
\hline DiNP & & 0.30 & 0.47 & 4.52 & 85.1 & 150 \\
\hline BPA & & 0.01 & 0.02 & 0.10 & 0.75 & 50 \\
\hline \multicolumn{7}{|c|}{$\begin{array}{l}\text { Estimated (minimum) daily excretion of } \\
\text { parabens and phenols, except BPA } \\
\text { ( } \mu \text { g/kg BW per day), } n=181\end{array}$} \\
\hline $\mathrm{MeP}$ & & 0.07 & 0.32 & 6.63 & 53.3 & \\
\hline EtP & & & 0.01 & 0.65 & 2.46 & \\
\hline$n-\operatorname{PrP}$ & & 0.01 & 0.08 & 2.57 & 5.46 & \\
\hline$n$-BuP & & & & 0.19 & 1.08 & \\
\hline TCS & & $<0.01$ & 0.01 & 7.65 & 27.7 & \\
\hline TCCB & & & $<0.01$ & 0.01 & 0.04 & \\
\hline BP-3 & & 0.02 & 0.04 & 16.4 & 91.4 & \\
\hline $2,4-\mathrm{DCP}^{\mathrm{b}}$ & & $<0.01$ & $<0.01$ & 0.02 & 0.06 & \\
\hline $2,5-\mathrm{DCP} \mathrm{P}^{\mathrm{b}}$ & & & $<0.01$ & 0.02 & 0.22 & \\
\hline $2,4,5$-ТСР & & & $<0.01$ & 0.01 & 0.07 & \\
\hline 2-PP & & & $<0.01$ & 0.01 & 0.02 & \\
\hline
\end{tabular}

BW, body weight; LOD, limit of detection; $n$, number of samples; Empty cells, not estimated because of urinary concentration $<$ LOD. ${ }^{\mathrm{a}} \mathrm{TDI}$, tolerable daily intake ( $\mu \mathrm{g} / \mathrm{kg} \mathrm{BW}$ per day) (European Food Safety Authority (EFSA) 2005a, 2005b, 2005c, 2005d, 2010). ${ }^{\mathrm{b}} n=150$. 
Table 4 Hazard quotients (HQ) and hazard indexes (HI) based on EFSAs TDI values.

\begin{tabular}{lrrrrr}
\hline & & \multicolumn{3}{c}{ Percentiles (HQs) } & \\
\cline { 3 - 5 } Compound & \multicolumn{1}{c}{ Min. HQ } & \multicolumn{1}{c}{25} & \multicolumn{1}{c}{50} & \multicolumn{1}{c}{95} & Max. HQ \\
\hline DnBP & 0.01 & 0.03 & 0.04 & 0.12 & 0.35 \\
BBzP & $<0.01$ & $<0.01$ & $<0.01$ & $<0.01$ & 0.01 \\
DEHP & $<0.01$ & 0.01 & 0.02 & 0.04 & 0.11 \\
HI & 0.01 & 0.04 & 0.06 & 0.16 & 0.37 \\
\hline
\end{tabular}

Unfortunately, the study design did not permit to have a more accurate maternal weight at the precise time point of urine sampling.

For phthalate metabolites and BPA, human FUE factors exist, which can be used to estimate a DI based on an estimated daily urinary excretion. However, these FUEs are derived from small studies on non-pregnant adult volunteers (Anderson et al. 2001, 2011), and FUEs in pregnant women may be different dependent on gestational age. The DI estimates of phthalate diesters are in general lower than that found in a previous study on American pregnant women (Marsee et al. 2006). Owing to lack of human pharmacokinetic information for the remaining chemicals, we could not calculate an estimated DI and were restricted to estimate daily excretion instead. In contrast to BPA, which is mainly excreted as conjugated forms and urinary phthalate metabolites, which can be calculated back to the parent compounds; this is not possible for parabens. Several, in vitro, animal and a few human studies have shown that a major part of orally administered paraben is excreted in urine as the unspecific metabolite, p-hydroxybenzoic acid, while only a minor part is excreted as free paraben and its glucuronic and sulphuric acid conjugates (Soni et al. 2005, Ye et al. 2006, CIR Expert Panel 2008). Following skin application, a minor part of the parabens was excreted in urine as the parent paraben in free (unconjugated) and conjugated form (glucuronidated and sulphated) (Janjua et al. 2007). Hence, as our estimated daily excretion of parabens is based on the fraction that was excreted as the conjugated and unconjugated parent compound, it most likely only represents a minor fraction of the true exposure and as such is a very conservative estimate. Overall, we believe that our estimated DIs and daily excretions are conservative estimates.

The EFSA has provided estimated TDIs for DnBP, BBzP, DEHP, DiNP and BPA. These TDIs are based on no observed adverse effect levels in toxicological studies on animals, to which uncertainty factors are applied to adjust for potential species differences in susceptibility. None of the estimated DIs for the individual compounds exceeded their respective TDI. The estimated DI of DnBP was closest to the TDI, but the median DI was still 24 times and the 95 percentile DI nine times below the TDI. No TDI has been given by EFSA for DiBP, although this chemical has been shown to have similar antiandrogenic effects as DnBP in animal studies (Borch et al. 2006), which suggests that both forms of DBP can contribute to adverse effects.

We found that pregnant women from the general population are simultaneously exposed to the majority of the investigated chemicals. Animal experiments have shown that low dose exposures to compounds affecting the same hormone axis can cause dose additive effects (Christiansen et al. 2009, 2012). To quantitatively assess the human risk of chemicals, the ratio between the actual level of exposure (our estimated DI) and a tolerable level of exposure (TDI estimate) is traditionally used. This ratio is referred to as the $\mathrm{HQ}$ and a $\mathrm{HQ}$ with a value of more than one indicates a risk. For DnBP, BBzP and DEHP, the EFSA TDIs are all based on anti-androgenic effects during foetal development allowing us to assess the combined risk of these compounds expressed as the $\mathrm{HI}$. Using this approach, the 95 percentile $\mathrm{HI}$ for the combined anti-androgenic effects was 0.16; still more

Table 5 Phenol and paraben studies reporting median/GM of phenols and parabens ( $\mu \mathrm{g} / \mathrm{l})$ in spot urine samples of pregnant women.

\begin{tabular}{|c|c|c|c|c|c|c|c|c|c|c|}
\hline \multirow[b]{2}{*}{ Country (reference) } & \multirow[b]{2}{*}{ Sampling years } & \multirow[b]{2}{*}{ Sample size $(n)$} & & \multicolumn{3}{|c|}{ Phenols } & \multicolumn{4}{|c|}{ Parabens } \\
\hline & & & & BPA & TCS & BP-3 & $\mathrm{MeP}$ & EtP & $n$-PrP & $n$-BuP \\
\hline Denmark (current study) & 2011 & 200 & Median & 1.38 & 0.70 & 3.20 & 20.7 & 1.01 & 4.17 & $<\mathrm{LOD}$ \\
\hline $\begin{array}{l}\text { The Netherlands } \\
\text { (Ye et al. 2008) }\end{array}$ & 2004-2006 & 100 & Median & 1.2 & & & & & & \\
\hline USA (Braun et al. 2011) & 2003-2006 & 370 & Median & 1.8 & & & & & & \\
\hline Norway (Ye et al. 2009) & 2004 & $\begin{array}{l}\text { Ten pooled samples } \\
\text { with } 11 \text { individual } \\
\text { samples in each pool }\end{array}$ & GM & 2.81 & & & & & & \\
\hline Spain (Casas et al. 2011) & 2004-2008 & 120 & Median & 2.2 & 6.1 & 3.4 & 191 & 8.8 & $29.8^{\mathrm{a}}$ & $2.4^{\mathrm{a}}$ \\
\hline USA (Wolff et al. 2008) & 1998-2002 & 367 & Median & 1.3 & 11.0 & 7.5 & & & & \\
\hline $\begin{array}{l}\text { USA (Woodruff et al. } \\
\text { 2004) }\end{array}$ & 2003-2004 & 86 & Median & 2.7 & 8.2 & 16.9 & & & & \\
\hline $\begin{array}{l}\text { France (Philippat et al. } \\
\text { 2012) }\end{array}$ & 2002-2006 & 191 & Median & 2.7 & 24.1 & 1.7 & 97.8 & 4.1 & $12.5^{\mathrm{a}}$ & $1.7^{\mathrm{a}}$ \\
\hline
\end{tabular}

GM, geometrical mean.

${ }^{\mathrm{a} N o}$ information provided whether the normal or isoform of the parabens is reported for PrP and BuP. 


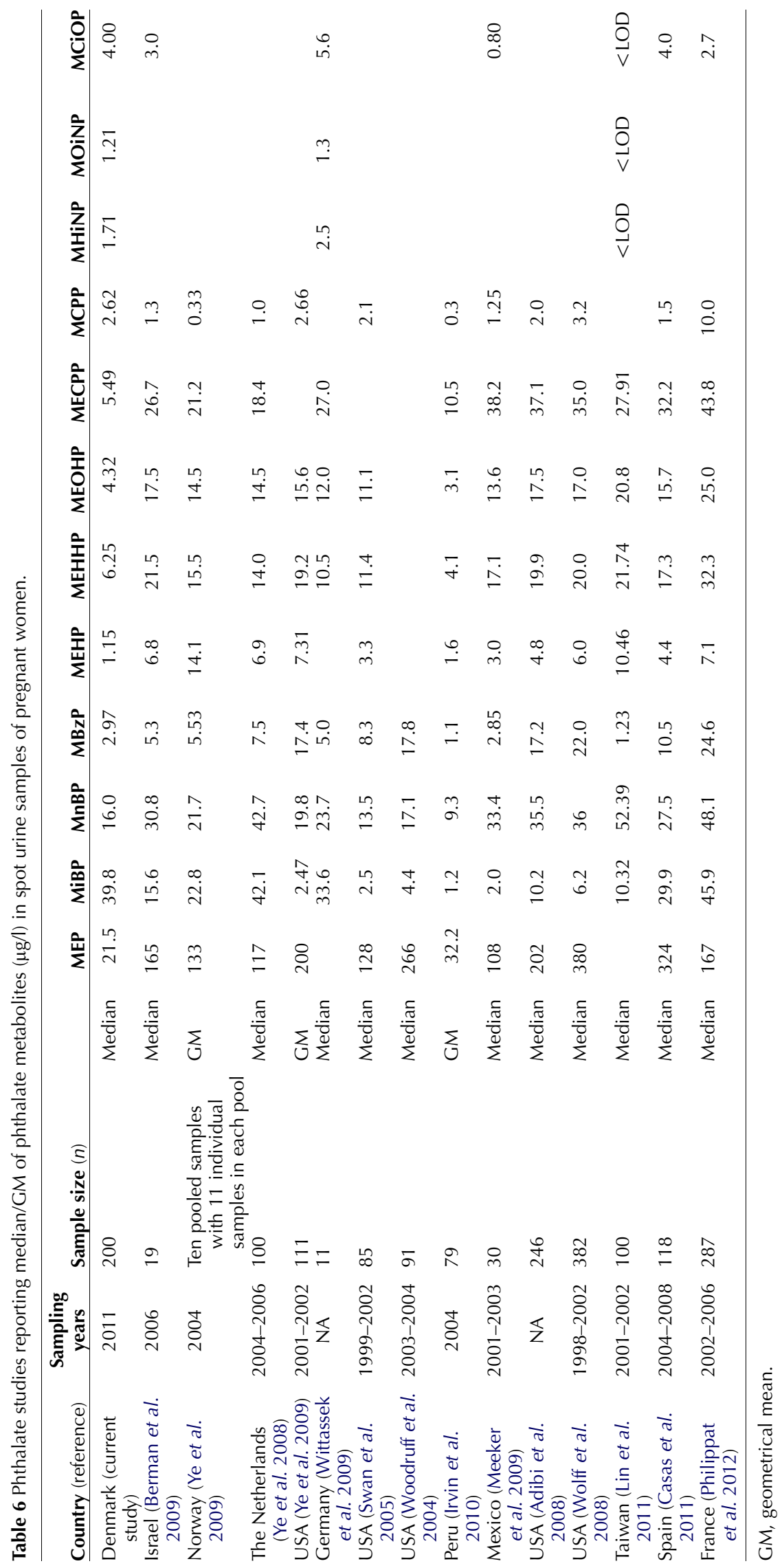


than six times below 1. However, phthalates are not the only anti-androgenic compounds to which humans are exposed. For a thorough assessment of the cumulative risk of exposure to chemicals with anti-androgenic effects, other compounds should be included. BPA, TCS, several parabens, and various pesticides and biocides have shown also to possess anti-androgenic properties (Chen et al. 2007, Luccio-Camelo \& Prins 2011). With $37 \%$ of the $\mathrm{HI}$ for anti-androgenic effects already taken up by only three phthalates in the most exposed woman (maximum), there is not much room left for additional exposure to anti-androgens.

A growing number of animal and epidemiological studies suggest adverse endocrine-disrupting effects on human health associated with exposure to many of the non-persistent EDCs measured in this study, encompassing effects on growth, reproductive development and thyroid function (Swan et al. 2005, Main et al. 2006, vom Saal et al. 2007, Chapin et al. 2008, Wolff et al. 2008, Boas et al. 2010, Chevrier et al. 2012, Philippat et al. 2012). In this context, it raises concern that we found detectable levels of phthalate metabolites, parabens and phenols in almost all pregnant women.

\section{Conclusion}

Our estimated DIs of different phthalates and BPA were below their individual TDI. However, a high individual exposure to one chemical was often associated with a high exposure to others and the possibility of combination effects of multiple simultaneous exposures cannot be excluded. Current toxicological risk assessments in humans do not account for combination effects of exposures, thus potentially underestimating the true cumulative risk for the developing foetus.

\section{Declaration of interest}

The authors declare that there is no conflict of interest that could be perceived as prejudicing the impartiality of the research reported.

\section{Funding}

This work was supported by the Danish Centre for Hormone Disrupting Chemicals, the Danish Foundation for Scientific Innovation and Technology (09-067180), Ronald McDonald Children Foundation, K A Rohde's and Wife's Foundation, Odense University Hospital and Region of Southern Denmark, Danielsen Foundation, The Danish Council for Strategic Research, Programme Commission on Health, Food and Welfare (2101-08-0058) and Odense Patient data Exploratory Network (OPEN). The LC-MS/MS equipment was financially supported by the Velux Foundation, Augustinus Foundation and Svend Andersen Foundation. This article is based on work presented at the 7th Copenhagen Workshop on Endocrine Disrupters, which was supported by the Danish Ministry of the Environment - Environmental Protection Agency. Publication of this special issue was supported by the Society for Reproduction and Fertility. K Tefre de Renzy-Martin, J S Christensen, $\mathrm{H}$ Boye Kyhl,T Barington and S Husby have no relationship with any sponsors of COW meeting, Danish Ministry of Environment and Environment Protection Agency.

\section{Acknowledgements}

The authors are grateful to all participants in the study. They appreciate the skilled technical assistance of Ole Nielsen, Department of Growth and Reproduction, Rigshospitalet, Denmark, in the analysis of chemical compounds and the Department of Clinical Biochemistry, Rigshospitalet, Denmark for analysing urinary creatinine.

\section{References}

Adibi JJ, Whyatt RM, Williams PL, Calafat AM, Camann D, Herrick R, Nelson H, Bhat HK, Perera FP, Silva MJ et al. 2008 Characterization of phthalate exposure among pregnant women assessed by repeat air and urine samples. Environmental Health Perspectives 116 467-473. (doi:10.1289/ehp.10749)

Anderson WA, Castle L, Scotter MJ, Massey RC \& Springall C 2001 A biomarker approach to measuring human dietary exposure to certain phthalate diesters. Food Additives and Contaminants 18 1068-1074. (doi:10.1080/02652030110050113)

Anderson WA, Castle L, Hird S, Jeffery J \& Scotter MJ 2011 A twentyvolunteer study using deuterium labelling to determine the kinetics and fractional excretion of primary and secondary urinary metabolites of di-2-ethylhexylphthalate and di-iso-nonylphthalate. Food and Chemical Toxicology 49 2022-2029. (doi:10.1016/j.fct.2011.05.013)

Barr DB, Bishop A \& Needham LL 2007 Concentrations of xenobiotic chemicals in the maternal-fetal unit. Reproductive Toxicology 23 260-266. (doi:10.1016/j.reprotox.2007.03.003)

Berman T, Hochner-Celnikier D, Calafat AM, Needham LL, Amitai Y, Wormser U \& Richter E 2009 Phthalate exposure among pregnant women in Jerusalem, Israel: results of a pilot study. Environment International 35 353-357. (doi:10.1016/j.envint.2008.08.010)

Boas M, Frederiksen H, Feldt-Rasmussen U, Skakkebaek NE, Hegedus L, Hilsted L, Juul A \& Main KM 2010 Childhood exposure to phthalates: associations with thyroid function, insulin-like growth factor I, and growth. Environmental Health Perspectives 118 1458-1464. (doi:10.1289/ehp.0901331)

Boberg J, Taxvig C, Christiansen S \& Hass U 2010 Possible endocrine disrupting effects of parabens and their metabolites. Reproductive Toxicology 30 301-312. (doi:10.1016/j.reprotox.2010.03.011)

Borch J, Axelstad M, Vinggaard AM \& Dalgaard M 2006 Diisobutyl phthalate has comparable anti-androgenic effects to di- $n$-butyl phthalate in fetal rat testis. Toxicology Letters 163 183-190. (doi:10.1016/j.toxlet. 2005.10.020)

Bradman A, Barr DB, Claus Henn BG, Drumheller T, Curry C \& Eskenazi B 2003 Measurement of pesticides and other toxicants in amniotic fluid as a potential biomarker of prenatal exposure: a validation study. Environmental Health Perspectives 111 1779-1782. (doi:10.1289/ehp.6259)

Braun JM, Kalkbrenner AE, Calafat AM, Bernert JT, Ye X, Silva MJ, Barr DB, Sathyanarayana S \& Lanphear BP 2011 Variability and predictors of urinary bisphenol A concentrations during pregnancy. Environmental Health Perspectives 119 131-137. (doi:10.1289/ehp.1002366)

Calafat AM, Ye X, Wong LY, Bishop AM \& Needham LL 2006 Urinary concentrations of four parabens in the U.S. population: NHANES 20052006. Environmental Health Perspectives 118 679-685. (doi:10.1289/ ehp.0901560)

Casas L, Fernandez MF, Llop S, Guxens M, Ballester F, Olea N, Irurzun MB, Rodriguez LS, Riano I, Tardon A et al. 2011 Urinary concentrations of 
phthalates and phenols in a population of Spanish pregnant women and children. Environment International 37 858-866. (doi:10.1016/j.envint. 2011.02.012)

Chapin RE, Adams J, Boekelheide K, Gray LE Jr, Hayward SW, Lees PS, McIntyre BS, Portier KM, Schnorr TM, Selevan SG et al. 2008 NTPCERHR, expert panel report on the reproductive and developmental toxicity of bisphenol A. Birth Defects Research. Part B, Developmental and Reproductive Toxicology 83 157-395. (doi:10.1002/bdrb.20147)

Chen J, Ahn KC, Gee NA, Gee SJ, Hammock BD \& Lasley BL 2007 Antiandrogenic properties of parabens and other phenolic containing small molecules in personal care products. Toxicology and Applied Pharmacology 221 278-284. (doi:10.1016/j.taap.2007.03.015)

Chevrier C, Petit C, Philippat C, Mortamais M, Slama R, Rouget F, Calafat AM, Ye X, Silva MJ, Charles MA et al. 2012 Maternal urinary phthalates and phenols and male genital anomalies. Epidemiology 23 353-356. (doi:10.1097/EDE.0b013e318246073e)

Christiansen S, Scholze M, Dalgaard M, Vinggaard AM, Axelstad M, Kortenkamp A \& Hass U 2009 Synergistic disruption of external male sex organ development by a mixture of four antiandrogens. Environmental Health Perspectives 117 1839-1846. (doi:10.1289/ehp.0900689)

Christiansen S, Kortenkamp A, Axelstad M, Boberg J, Scholze M, Jacobsen PR, Faust M, Lichtensteiger W, Schlumpf M, Burdorf A et al. 2012 Mixtures of endocrine disrupting contaminants modelled on human high end exposures: an exploratory study in rats. International Journal of Andrology 35 303-316. (doi:10.1111/j.1365-2605.2011. 01242.x)

CIR Expert Panel 2008 Final amended report on the safety assessment of methylparaben, ethylparaben, propylparaben, isopropylparaben, butylparaben, isobutylparaben, and benzylparaben as used in cosmetic products. International Journal of Toxicology 27 (Suppl 4) 1-82.

Desdoits-Lethimonier C, Albert O, Le BB, Perdu E, Zalko D, Courant F, Lesne L, Guille F, Dejucq-Rainsford N \& Jegou B 2012 Human testis steroidogenesis is inhibited by phthalates. Human Reproduction 27 1451-1459. (doi:10.1093/humrep/des069)

European Food Safety Authority (EFSA) 2004 Opinion of the Scientific Panel on Food Additives, Flavourings, Processing Aids and Materials in Contact with Food on a Request from the Commission related to para hydroxybenzoates. EFSA Journa/ 83 1-26, http://www.efsa.europa.eu/en/ efsajournal/pub/83.htm

European Food Safety Authority (EFSA), 2005a Statement of the Scientific Panel on Food Additives, Flavourings, Processing Aids and Materials in Contact with Food on a request from the Commission on the possibility of allocating a group-TDI for Butylbenzylphthalate (BBP), di-Butylphthalate (DBP), Bis(2-ethylhexyl) phthalate (DEHP), di-Isononylphthalate (DINP) and di-Isodecylphthalate (DIDP), http://www.efsa.europa.eu/en/efsajournal/pub/747.htm

European Food Safety Authority (EFSA) 2005b Opinion of the Scientific Panel on Food Additives, Flavourings, Processing Aids and Material in Contact with Food (AFC) on a request from the Commission related to Di-Butylphthalate (DBP) for use in food contact materials. EFSA Journal 242 1-17, http://www.efsa.europa.eu/en/efsajournal/pub/242.htm

European Food Safety Authority (EFSA) 2005c Opinion of the Scientific Panel on Food Additives, Flavourings, Processing Aids and Materials in Contact with Food (AFC) on a request from the Commission related to Di-isononylphthalate (DINP) for use in food contact materials. EFSA Journal 244 1-18, http://www.efsa.europa.eu/it/scdocs/doc/244.pdf

European Food Safety Authority (EFSA) 2005d Opinion of the Scientific Panel on Food Additives, Flavourings, Processing Aids and Materials in Contact with Food (AFC) on a request from the Commission related to Bis(2-ethylhexyl)phthalate (DEHP) for use in food contact materials. EFSA Journal 243 1-20, http://www.efsa.europa.eu/en/efsajournal/pub/ 243.htm

European Food Safety Authority (EFSA) 2010 Scientific Opinion on Bisphenol A: evaluation of a study investigating its neurodevelopmental toxicity, review of recent scientific literature on its toxicity and advice on the Danish risk assessment of Bisphenol A. EFSA Journal 8 1829, http:// www.efsa.europa.eu/en/efsajournal/pub/1829.htm

Fisher JW, Twaddle NC, Vanlandingham M \& Doerge DR 2011 Pharmacokinetic modeling: prediction and evaluation of route dependent dosimetry of bisphenol A in monkeys with extrapolation to humans. Toxicology and Applied Pharmacology 257 122-136. (doi:10.1016/ j.taap.2011.08.026)
Frederiksen H, Taxvig C, Hass U, Vinggaard AM \& Nellemann C 2008 Higher levels of ethyl paraben and butyl paraben in rat amniotic fluid than in maternal plasma after subcutaneous administration. Toxicological Sciences 106 376-383. (doi:10.1093/toxsci/kfn171)

Frederiksen H, Jorgensen N \& Andersson AM 2010 Correlations between phthalate metabolites in urine, serum, and seminal plasma from young Danish men determined by isotope dilution liquid chromatography tandem mass spectrometry. Journal of Analytical Toxicology 34 400-410. (doi:10.1093/jat/34.7.400)

Frederiksen H, Jorgensen N \& Andersson AM 2011 Parabens in urine, serum and seminal plasma from healthy Danish men determined by liquid chromatography-tandem mass spectrometry (LC-MS/MS). Journal of Exposure Science and Environmental Epidemiology 21 262-271. (doi:10.1038/jes.2010.6)

Frederiksen H, Aksglaede L, Sorensen K, Nielsen O, Main KM, Skakkebaek N, Juul A \& Andersson A 2013 Bisphenol A and other phenols in urine from Danish children and adolescents analyzed by isotope diluted TurboFlowLC-MS/MS. International Journal of Hygiene and Environmental Health 216 710-720. (doi:10.1016/j.ijheh.2013.01.007)

Gallery EDM, Ross M \& Gyory AZ 1996 24-hour urinary creatinine excretion is not altered in human pregnancy. Hypertension in Pregnancy 15 257-261. (doi:10.3109/10641959609015709)

Golden R, Gandy J \& Vollmer G 2005 A review of the endocrine activity of parabens and implications for potential risks to human health. Critical Reviews in Toxicology 35 435-458. (doi:10.1080/ 10408440490920104)

Gray LE Jr, Wilson VS, Stoker T, Lambright C, Furr J, Noriega N, Howdeshell K, Ankley GT \& Guillette L 2006 Adverse effects of environmental antiandrogens and androgens on reproductive development in mammals. International Journal of Andrology 29 96-104. (doi:10.1111/j.1365-2605.2005.00636.x)

Henry ND \& Fair PA 2013 Comparison of in vitro cytotoxicity, estrogenicity and anti-estrogenicity of triclosan, perfluorooctane sulfonate and perfluorooctanoic acid. Journal of Applied Toxicology 33 265-272. (doi:10.1002/jat.1736)

Ikezuki Y, Tsutsumi O, Takai Y, Kamei Y \& Taketani Y 2002 Determination of bisphenol A concentrations in human biological fluids reveals significant early prenatal exposure. Human Reproduction 17 2839-2841. (doi:10.1093/humrep/17.11.2839)

Irvin EA, Calafat AM, Silva MJ, Aguilar-Villalobos M, Needham LL, Hall DB, Cassidy B \& Naeher LP 2010 An estimate of phthalate exposure among pregnant women living in Trujillo, Peru. Chemosphere $\mathbf{8 0}$ 1301-1307. (doi:10.1016/j.chemosphere.2010.06.048)

Janjua NR, Mortensen GK, Andersson AM, Kongshoj B, Skakkebaek NE \& Wulf HC 2007 Systemic uptake of diethyl phthalate, dibutyl phthalate, and butyl paraben following whole-body topical application and reproductive and thyroid hormone levels in humans. Environmental Science \& Technology 41 5564-5570. (doi:10.1021/es0628755)

Jensen MS, Norgaard-Pedersen B, Toft G, Hougaard DM, Bonde JP, Cohen A, Thulstrup AM, Ivell R, Nand-Ivell R, Lindh CH et al. 2012 Phthalates and perfluorooctanesulfonic acid in human amniotic fluid: temporal trends and timing of amniocentesis in pregnancy. Environmental Health Perspectives 120 897-903. (doi:10.1289/ehp.1104522)

Jung EM, An BS, Choi KC \& Jeung EB 2012 Potential estrogenic activity of triclosan in the uterus of immature rats and rat pituitary $\mathrm{GH} 3$ cells. Toxicology Letters 208 142-148. (doi:10.1016/j.toxlet.2011.10.017)

Koch HM \& Calafat AM 2009 Human body burdens of chemicals used in plastic manufacture. Philosophical Transactions of the Royal Society of London. Series B, Biological Sciences 364 2063-2078. (doi:10.1098/ rstb.2008.0208)

Krause M, Klit A, Blomberg JM, Soeborg T, Frederiksen H, Schlumpf M, Lichtensteiger W, Skakkebaek NE \& Drzewiecki KT 2012 Sunscreens: are they beneficial for health? An overview of endocrine disrupting properties of UV-filters. International Journal of Andrology 35 424-436. (doi:10.1111/j.1365-2605.2012.01280.x)

Li J, Ma M \& Wang Z 2010 In vitro profiling of endocrine disrupting effects of phenols. Toxicology In Vitro 24 201-207. (doi:10.1016/j.tiv. 2009.09.008)

Lin S, Ku HY, Su PH, Chen JW, Huang PC, Angerer J \& Wang SL 2011 Phthalate exposure in pregnant women and their children in central Taiwan. Chemosphere 82 947-955. (doi:10.1016/j.chemosphere. 2010.10.073) 
Luccio-Camelo DC \& Prins GS 2011 Disruption of androgen receptor signaling in males by environmental chemicals. Journal of Steroid Biochemistry and Molecular Biology 127 74-82. (doi:10.1016/j.jsbmb. 2011.04.004)

Main KM, Mortensen GK, Kaleva MM, Boisen KA, Damgaard IN, Chellakooty M, Schmidt IM, Suomi AM, Virtanen HE, Petersen DV et al. 2006 Human breast milk contamination with phthalates and alterations of endogenous reproductive hormones in infants three months of age. Environmental Health Perspectives 114 270-276. (doi:10.1289/ ehp.8075)

Marsee K, Woodruff TJ, Axelrad DA, Calafat AM \& Swan SH 2006 Estimated daily phthalate exposures in a population of mothers of male infants exhibiting reduced anogenital distance. Environmental Health Perspectives 114 805-809. (doi:10.1289/ehp.8663)

Meeker JD, Hu H, Cantonwine DE, Lamadrid-Figueroa $H$, Calafat AM, Ettinger AS, Hernandez-Avila M, Loch-Caruso R \& Tellez-Rojo MM 2009 Urinary phthalate metabolites in relation to preterm birth in Mexico city. Environmental Health Perspectives 117 1587-1592. (doi:10.1289/ ehp.0800522)

Morck TJ, Sorda G, Bechi N, Rasmussen BS, Nielsen JB, letta F, Rytting E, Mathiesen L, Paulesu L \& Knudsen LE 2010 Placental transport and in vitro effects of bisphenol A. Reproductive Toxicology 30 131-137. (doi:10.1016/j.reprotox.2010.02.007)

Mose T, Mortensen GK, Hedegaard M \& Knudsen LE 2007 Phthalate monoesters in perfusate from a dual placenta perfusion system, the placenta tissue and umbilical cord blood. Reproductive Toxicology 23 83-91. (doi:10.1016/j.reprotox.2006.08.006)

Philippat C, Mortamais M, Chevrier C, Petit C, Calafat AM, Ye X, Silva MJ, Brambilla C, Pin I, Charles MA et al. 2012 Exposure to phthalates and phenols during pregnancy and offspring size at birth. Environmental Health Perspectives 120 464-470. (doi:10.1289/ehp.1103634)

Rastogi SC, Schouten A, de Kruijf N \& Weijland JW 1995 Contents of methyl-, ethyl-, propyl-, butyl- and benzylparaben in cosmetic products. Contact Dermatitis 32 28-30. (doi:10.1111/j.1600-0536. 1995.tb00836.x)

Rodriguez PE \& Sanchez MS 2010 Maternal exposure to triclosan impairs thyroid homeostasis and female pubertal development in Wistar rat offspring. Journal of Toxicology and Environmental Health. Part A 73 1678-1688. (doi:10.1080/15287394.2010.516241)

vom Saal FS, Akingbemi BT, Belcher SM, Birnbaum LS, Crain DA, Eriksen M, Farabollini F, Guillette LJ Jr, Hauser R, Heindel JJ et al. 2007 Chapel Hill bisphenol A expert panel consensus statement: integration of mechanisms, effects in animals and potential to impact human health at current levels of exposure. Reproductive Toxicology 24 131-138. (doi:10.1016/j.reprotox.2007.07.005)

Soeborg T, Frederiksen H \& Andersson AM 2012 Cumulative risk assessment of phthalate exposure of Danish children and adolescents using the hazard index approach. International Journal of Andrology 35 245-252. (doi:10.1111/j.1365-2605.2011.01240.x)

Soni MG, Carabin IG \& Burdock GA 2005 Safety assessment of esters of p-hydroxybenzoic acid (parabens). Food and Chemical Toxicology 43 985-1015. (doi:10.1016/j.fct.2005.01.020)

Swan SH, Main KM, Liu F, Stewart SL, Kruse RL, Calafat AM, Mao CS, Redmon JB, Ternand CL, Sullivan S et al. 2005 Decrease in anogenital distance among male infants with prenatal phthalate exposure Environmental Health Perspectives 113 1056-1061. (doi:10.1289/ehp. 8100)

Vandenberg LN, Maffini MV, Sonnenschein C, Rubin BS \& Soto AM 2009 Bisphenol-A and the great divide: a review of controversies in the field of endocrine disruption. Endocrine Reviews 30 75-95. (doi:10.1210/ er.2008-0021)

Volkel W, Colnot T, Csanady GA, Filser JG \& Dekant W 2002 Metabolism and kinetics of bisphenol a in humans at low doses following oral administration. Chemical Research in Toxicology 15 1281-1287. (doi:10.1021/tx025548t)

Wittassek M, Angerer J, Kolossa-Gehring M, Schafer SD, Klockenbusch W, Dobler L, Gunsel AK, Muller A \& Wiesmuller GA 2009 Fetal exposure to phthalates - a pilot study. International Journal of Hygiene and Environmental Health 212 492-498. (doi:10.1016/j.ijheh.2009.04.001)

Wittassek M, Koch HM, Angerer J \& Bruning T 2011 Assessing exposure to phthalates - the human biomonitoring approach. Molecular Nutrition \& Food Research 55 7-31. (doi:10.1002/mnfr.201000121)

Wolff MS, Engel SM, Berkowitz GS, Ye X, Silva MJ, Zhu C, Wetmur J \& Calafat AM 2008 Prenatal phenol and phthalate exposures and birth outcomes. Environmental Health Perspectives 116 1092-1097. (doi:10.1289/ehp.11007)

Woodruff TJ, Zota AR \& Schwartz JM 2004 Environmental chemicals in pregnant women in the United States: NHANES 2003-2004. Environmental Health Perspectives 119 878-885. (doi:10.1289/ehp.1002727)

Ye X, Bishop AM, Reidy JA, Needham LL \& Calafat AM 2006 Parabens as urinary biomarkers of exposure in humans. Environmental Health Perspectives 114 1843-1846.

Ye X, Pierik FH, Hauser R, Duty S, Angerer J, Park MM, Burdorf A, Hofman A, Jaddoe VW, Mackenbach JP et al. 2008 Urinary metabolite concentrations of organophosphorous pesticides, bisphenol A and phthalates among pregnant women in Rotterdam, The Netherlands: the Generation R Study. Environmental Research 108 260-267. (doi:10.1016/j.envres.2008.07.014)

Ye X, Pierik FH, Angerer J, Meltzer HM, Jaddoe VW, Tiemeier $H_{\text {, }}$ Hoppin JA \& Longnecker MP 2009 Levels of metabolites of organophosphate pesticides, phthalates, and bisphenol A in pooled urine specimens from pregnant women participating in the Norwegian Mother and Child Cohort Study (MoBa). International Journal of Hygiene and Environmental Health 212 481-491. (doi:10.1016/j.ijheh. 2009.03.004)

Ye X, Wong LY, Bishop AM \& Calafat AM 2011 Variability of urinary concentrations of bisphenol $\mathrm{A}$ in spot samples, first morning voids, and 24-hour collections. Environmental Health Perspectives 119 983-988. (doi:10.1289/ehp.1002701)

Zhang X, Zha J, Li W, Yang L \& Wang Z 2008 Effects of 2,4-dichlorophenol on the expression of vitellogenin and estrogen receptor genes and physiology impairments in Chinese rare minnow (Gobiocypris rarus). Environmental Toxicology 23 694-701. (doi:10.1002/tox.20375)

Received 18 September 2013

Accepted 26 November 2013 